\title{
Nanoparticle albumin-bound paclitaxel and PD-1 inhibitor (sintilimab) combination therapy for soft tissue sarcoma: a retrospective study
}

Zhichao Tian ${ }^{1 *}$, Shuping Dong ${ }^{1}$, Yang Yang ${ }^{2}$, Shilei Gao ${ }^{1}$, Yonghao Yang ${ }^{3}$, Jinpo Yang ${ }^{4}$, Peng Zhang ${ }^{1}$, Xin Wang ${ }^{1}$ and Weitao Yao ${ }^{1}$

\begin{abstract}
Background: There is increasing evidence that combination therapy with nanoparticle albumin-bound paclitaxel (nab-paclitaxel) and programmed cell death protein 1 (PD-1) inhibitor is safe and efficacious in treating many types of malignant tumors. However, clinical data demonstrating the effect of this treatment combination for patients with metastatic soft tissue sarcoma (STS) are currently limited.

Methods: The clinical data of patients with metastatic STS who received nab-paclitaxel plus PD-1 inhibitor (sintilimab) therapy between January 2019 and February 2021 were retrospectively analyzed. The effectiveness and safety of the combined treatment were evaluated in terms of the median progression-free survival (PFS), estimated using the Kaplan-Meier method. The univariate Cox proportional hazards model was used to analyze the relationship between clinicopathological parameters and PFS. All statistical analyses were two-sided; $P<0.05$ was considered statistically significant.
\end{abstract}

Results: A total of 28 patients treated with nab-paclitaxel plus sintilimab were enrolled in this study. The objective response rate was $25 \%$, the disease control rate was $50 \%$, and the median PFS was 2.25 months $(95 \% \mathrm{Cl}=1.8-$ 3.0 months). The most common grade 1 or 2 adverse events (AEs) were alopecia (89.3\%; 25/28), leukopenia (25.0\%; $7 / 28)$, fatigue $(21.4 \% ; 6 / 28)$, anemia $(21.4 \% ; 6 / 28)$, and nausea (21.4\%; 6/28). The most common grade 3 AEs were neutropenia $(10.7 \% ; 3 / 28)$ and peripheral neuropathy $(10.7 \% ; 3 / 28)$. No grade 4 AEs were observed. Among the present study cohort, patients with angiosarcoma $(n=5)$ had significantly longer PFS $(P=0.012)$ than patients with other pathological subtypes, including undifferentiated pleomorphic sarcoma $(n=7)$, epithelioid sarcoma $(n=5)$, fibrosarcoma $(n=4)$, synovial sarcoma $(n=3)$, leiomyosarcoma $(n=2)$, pleomorphic liposarcoma $(n=1)$, and rhabdomyosarcoma $(n=1)$; those who experienced three or more AEs had significantly longer median PFS than those who experienced less than three AEs $(P=0.018)$.

Conclusion: Nab-paclitaxel plus PD-1 inhibitor is a promising treatment regimen for advanced STS. Randomized controlled clinical trials are required to further demonstrate its efficacy and optimal application scenario.

\footnotetext{
*Correspondence: tianzhichaoyy@163.com

${ }^{1}$ Department of Bone and Soft Tissue, The Affiliated Cancer Hospital

of Zhengzhou University and Henan Cancer Hospital, Dongming Road

Zhengzhou 450008, Henan Province, China

Full list of author information is available at the end of the article
}

(C) The Author(s) 2022. Open Access This article is licensed under a Creative Commons Attribution 4.0 International License, which permits use, sharing, adaptation, distribution and reproduction in any medium or format, as long as you give appropriate credit to the original author(s) and the source, provide a link to the Creative Commons licence, and indicate if changes were made. The images or other third party material in this article are included in the article's Creative Commons licence, unless indicated otherwise in a credit line to the material. If material is not included in the article's Creative Commons licence and your intended use is not permitted by statutory regulation or exceeds the permitted use, you will need to obtain permission directly from the copyright holder. To view a copy of this licence, visit http://creativecommons.org/licenses/by/4.0/. The Creative Commons Public Domain Dedication waiver (http://creativecommons.org/publicdomain/zero/1.0/) applies to the data made available in this article, unless otherwise stated in a credit line to the data. 
Keywords: Nanoparticle albumin-bound paclitaxel, PD-1 inhibitor, Programmed cell death protein 1, Sintilimab, Soft tissue sarcoma, Angiosarcoma

\section{Background}

Soft tissue sarcomas (STSs) are malignant tumors originating from the mesenchymal tissue. This type of tumor occurs throughout the body and is typically characterized by an asymptomatic mass. Some STSs that grow too fast can cause pain by pressing on the surrounding tissue [1]. The preferred treatment for early and middle-stage STS is complete resection [2]. Approximately $50 \%$ of STSs metastasize primarily to the lungs via blood circulation despite surgery [3]. Although STS incidence is low (approximately 4 per 100,000), there are over 70 subtypes $[1,4]$. Despite each subtype of STS having different sensitivity to radiotherapy or chemotherapy, the first- and second-line chemotherapy regimen for advanced STS is doxorubicin and docetaxel plus gemcitabine, respectively $[2,3]$. However, the response rate for the aforementioned regimens is $<20 \%$, resulting in a median overall survival of approximately 12 months for patients with advanced STS [5-7]. Therefore, more effective therapies are urgently needed.

Nanoparticle albumin-bound paclitaxel (nab-paclitaxel) is a new type of taxane antineoplastic drug [8]. Compared with the other two major taxanes, paclitaxel and docetaxel, nab-paclitaxel is more water-soluble and bioavailable, and less toxic, thus improving its anti-tumor efficacy [8-10]. Nab-paclitaxel has been increasingly used to treat various types of malignant tumors [11-13]. Several recent reports suggest that nab-paclitaxel is effective in treating sarcomas and proved more effective than docetaxel, a second-line treatment for STS, in some subtypes [14-16].

As a new type of anti-tumor therapy, anti-programmed cell death protein 1 (PD-1) inhibitors have been widely used in STS treatment and research [17]. Although recent evidence shows that the response rate of PD-1 inhibitor monotherapy is low in patients with STS $[17,18]$, there have been encouraging reports of efficacy in some sarcoma subtypes [19]. The combination of PD-1 inhibitors with cytotoxic chemotherapy agents is a promising way to improve the efficacy of PD-1 inhibitors in the treatment of patients with malignant tumors, including STS $[18,20-22]$.

Combination therapy with nab-paclitaxel and PD-1 inhibitors has proven effective in treating patients with advanced lung cancer and melanoma [23-25]. However, the efficacy and safety of nab-paclitaxel combined with a PD-1 inhibitor for patients with STS have not been reported. We have extensive experience in the treatment of patients with advanced STS using nab-paclitaxel or PD-1 inhibitors [26, 27]. Some patients were treated with nab-paclitaxel plus a PD-1 inhibitor. In this study, we retrospectively collected and analyzed the clinical data of patients with advanced STS who were treated with nabpaclitaxel plus a PD-1 inhibitor to provide reference data for the diagnosis, treatment, and clinical trial design of advanced STS.

\section{Methods}

Patient enrolment and eligibility criteria

This was a retrospective study of patients with STS treated at the Affiliated Cancer Hospital of Zhengzhou University (Zhengzhou, China). All the patients received nab-paclitaxel plus a PD-1 inhibitor between January 2019 and February 2021. The patient eligibility criteria included: 1) histologically proven STS, 2) treatment with nab-paclitaxel plus PD-1 inhibitor, 3) locally unresectable or multiple metastases, 4) measurable lesions according to the response evaluation criteria in solid tumors (RECIST; version 1.1) [28], and 5) complete clinical data and statistical analysis. This analysis was descriptive, and the follow-up was extended to June 30, 2021.

\section{Treatment protocol}

The patients received $300 \mathrm{mg} / \mathrm{m}^{2}$ of nab-paclitaxel (Hengrui Pharmaceutical, Lianyungang, China) and $200 \mathrm{mg}$ of PD-1 inhibitor (sintilimab; Innovent Biologics, Suzhou, China) via a $30-$ min intravenous infusion on day 1 . The treatment was repeated every 3 weeks until progressive disease (PD) occurrence or unacceptable adverse events (AEs). If grade 3 or 4 AEs occurred, treatment was delayed for a maximum of 14 days until recovery.

\section{Evaluation of AEs and tumor responses}

We firstly reviewed the baseline the demographics and characteristics of STS patients enrolled in this study. According to the RECIST (version 1.1), the tumor responses evaluation was performed every 6 weeks, or immediately when there is a clear signal of PD was observed. Tumor responses were categorized as PD, stable disease (SD), partial response (PR) or complete response $(\mathrm{CR})$. The objective response rate (ORR) was defined as the sum of CR and PR rates. Disease control rate (DCR) was defined as the sum of the ORR and SD. PFS was defined the time from the date of the first nabpaclitaxel plus PD-1 inhibitor treatment to the date of PD was observed. The National Cancer Institute Common 
Terminology Criteria for Adverse Events (version 4.0) was used to assess the AEs. Finally, the relationship between clinical parameters and PFS was assessed.

\section{Statistical analysis}

Quantitative variables are presented as numerical values (percentages) and medians (ranges). Statistical analyses were performed using SPSS 21.0 (SPSS Inc., Chicago, IL, USA). The corresponding figures were drawn using GraphPad Prism 5.0 (GraphPad Software Inc., San Diego, CA, USA). PFS was estimated using the Kaplan-Meier method. Univariate Cox proportional hazards model was used to analyze the relationship between the clinicopathological parameters and PFS. All statistical analyses were two-sided, and a $P$ value of $<0.05$ was considered statistically significant.

\section{Results}

\section{Patient characteristics}

From January 2019 to February 2021, 28 patients (average age \pm standard deviation $=42.54 \pm 14.31$ years) with advanced STS, treated with nab-paclitaxel plus PD-1 inhibitor, were identified. The cohort included 13 men and 15 women (Table 1); all had an Eastern Cooperative Oncology Group performance status of 0 or 1 and stage IV disease. The histological subtypes included undifferentiated pleomorphic sarcoma $(n=7)$, angiosarcoma $(n=5)$, epithelioid sarcoma $(n=5)$, fibrosarcoma $(n=4)$, synovial sarcoma $(n=3)$, leiomyosarcoma $(n=2)$,

Table 1 Patient demographics and characteristics

\begin{tabular}{|c|c|c|c|c|c|c|c|c|}
\hline Patient No. & ECOG PS & Histological subtype & Stage & Primary site & Metastatic site & $\begin{array}{l}\text { Previous lines of } \\
\text { chemotherapy }\end{array}$ & Response & PFS (Months) \\
\hline 1 & 1 & UPS & IV & Head & Lung and bone & 1 & $P R$ & 5 \\
\hline 2 & 1 & UPS & IV & Extremities & Lung and lymph nodes & 1 & $P R$ & 3.5 \\
\hline 3 & 0 & UPS & IV & Extremities & Lung and bone & 2 & SD & 3 \\
\hline 4 & 0 & UPS & IV & Neck & Bone & 2 & SD & 2.5 \\
\hline 5 & 0 & UPS & IV & Extremities & Lung & 2 & PD & 2 \\
\hline 6 & 0 & UPS & IV & Extremities & Bone & 2 & PD & 1.8 \\
\hline 7 & 1 & UPS & IV & Extremities & Lung & 1 & PD & 1 \\
\hline 8 & 1 & Angiosarcoma & IV & Head & Liver & 2 & $C R$ & 15 \\
\hline 9 & 0 & Angiosarcoma & IV & Trunk & Bone & 2 & $P R$ & 7.8 \\
\hline 10 & 1 & Angiosarcoma & IV & Extremities & Lung & 2 & $P R$ & 4 \\
\hline 11 & 0 & Angiosarcoma & IV & Extremities & Lung & 2 & SD & 4.5 \\
\hline 12 & 0 & Angiosarcoma & IV & Trunk & Lung & 2 & PD & 2 \\
\hline 13 & 1 & Epithelioid sarcoma & IV & Extremities & Lung & 2 & $P R$ & 2.8 \\
\hline 14 & 1 & Epithelioid sarcoma & IV & Trunk & Lung and lymph nodes & 2 & SD & 3 \\
\hline 15 & 1 & Epithelioid sarcoma & IV & Trunk & Lung & 2 & SD & 2.8 \\
\hline 16 & 0 & Epithelioid sarcoma & IV & Extremities & Lung & 1 & PD & 1.8 \\
\hline 17 & 1 & Epithelioid sarcoma & IV & Extremities & Lung and bone & 2 & PD & 1.3 \\
\hline 18 & 1 & Fibrosarcoma & IV & Trunk & Lung & 2 & $P R$ & 4.3 \\
\hline 19 & 1 & Fibrosarcoma & IV & Extremities & Lung & 2 & SD & 2.5 \\
\hline 20 & 0 & Fibrosarcoma & IV & Extremities & Lung & 1 & PD & 1.5 \\
\hline 21 & 0 & Fibrosarcoma & IV & Extremities & Liver & 3 & PD & 1.3 \\
\hline 22 & 0 & Synovial sarcoma & IV & Neck & Lung & 2 & PD & 1.8 \\
\hline 23 & 0 & Synovial sarcoma & IV & Extremities & Lung & 2 & PD & 1.5 \\
\hline 24 & 1 & Synovial sarcoma & IV & Trunk & Lung & 3 & PD & 1.5 \\
\hline 25 & 0 & Leiomyosarcoma & IV & Extremities & Lung & 2 & SD & 2.8 \\
\hline 26 & 1 & Leiomyosarcoma & IV & Trunk & Liver & 1 & PD & 1.3 \\
\hline 27 & 0 & Pleomorphic liposarcoma & IV & Extremities & Lung & 2 & PD & 1.8 \\
\hline 28 & 1 & Rhabdomyosarcoma & IV & Head & Lung & 1 & PD & 1.5 \\
\hline
\end{tabular}

The clinical and pathologic stages are expressed according to the American Joint Committee on Cancer (8th Edition) TNM staging. Tumor responses were evaluated according to the Response Evaluation Criteria in Solid Tumors (version 1.1), and were categorized as CR Complete response, $P R$ Partial response, SD Stable disease, or PD Progressive disease. PFS Progression-free survival was calculated from the date of the first nab-paclitaxel plus PD-1 inhibitor treatment until the date of documented progression 
pleomorphic liposarcoma $(n=1)$, and rhabdomyosarcoma $(n=1)$. The primary tumor site was distributed throughout the body, but mainly in the extremities. Lung metastasis occurred first in most patients, and all had previously received $1-3$ lines of chemotherapy (Table 1 ).

\section{Effectiveness of therapy}

Of the 28 patients with advanced STS, one patient with angiosarcoma had a CR, six had a PR, and seven had SD (Tables 1 and 2; Fig. 1). The ORR, DCR, median-PFS, and 4-month PFS rate were 25, 50\%, 2.25 months (95\% CI; 1.8-3.0 months), and 17.9\% (Table 3; Fig. 1), respectively.

\section{Toxicity and safety}

In general, nab-paclitaxel plus PD-1 inhibitor therapy was relatively well tolerated (Table 4 ). The most common grade 1 or 2 AEs were alopecia $(89.3 \%$; $25 / 28)$, leukopenia (25.0\%; 7/28), fatigue (21.4\%; 6/28), anemia (21.4\%; 6/28), and nausea $(21.4 \% ; 6 / 28)$. The most common grade $3 \mathrm{AEs}$ were neutropenia $(10.7 \% ; 3 / 28)$ and peripheral neuropathy $(10.7 \% ; 3 / 28)$. No grade 4 AEs were observed. None of the patients received a reduced dose of nab-paclitaxel

Table 2 Responses of various histological subtypes to treatment

\begin{tabular}{lllll}
\hline Histological subtypes & \multicolumn{4}{l}{ Number of patients } \\
\cline { 2 - 5 } & CR & PR & SD & PD \\
\hline UPS $(n=7)$ & 0 & 2 & 2 & 3 \\
Angiosarcoma $(n=5)$ & 1 & 2 & 2 & 0 \\
Epithelioid sarcoma $(n=5)$ & 0 & 1 & 2 & 2 \\
Fibrosarcoma $(n=4)$ & 0 & 1 & 1 & 2 \\
Synovial sarcoma $(n=3)$ & 0 & 0 & 0 & 3 \\
Leiomyosarcoma $(n=2)$ & 0 & 0 & 1 & 1 \\
Pleomorphic liposarcoma $(n=1)$ & 0 & 0 & 0 & 1 \\
Rhabdomyosarcoma $(n=1)$ & 0 & 0 & 0 & 1 \\
Total & 1 & 6 & 8 & 13
\end{tabular}

Tumor responses were evaluated according to the Response Evaluation Criteria in Solid Tumors (version 1.1), and were categorized as $C R$ Complete response, $P R$ Partial response, SD Stable disease, or PD Progressive disease

Abbreviations: UPS Undifferentiated pleomorphic sarcoma or PD-1 inhibitor due to AEs, and no treatment-related deaths occurred.

\section{Univariate Cox regression analysis}

Univariate Cox regression analysis was performed to determine the relationship between the median PFS and clinical characteristics of the patients in this study (Fig. 2). Among our patient cohort, those with angiosarcoma had a significantly longer PFS than those with other pathological subtypes $(\mathrm{HR}=0.20,95 \% \mathrm{CI} 0.06$ $-0.70, P=0.012)$; those with the primary tumor site in the head region had a significantly longer PFS than those with the primary tumor at other sites $(\mathrm{HR}=0.20,95 \% \mathrm{CI}$ $0.04-0.99, P=0.048$ ); those who experienced three or more AEs had a significantly longer PFS than those who experienced less than three AEs $(\mathrm{HR}=0.36,95 \% \mathrm{CI} 0.16$ $0.84, P=0.018)$.

\section{Discussion}

In this study, we retrospectively reviewed and analyzed the clinical data of 28 patients with advanced STS who received nab-paclitaxel plus PD-1 inhibitor (sintilimab) treatment. The ORR, DCR, and median PFS were 25, $50 \%$, and 2.25 months, respectively. In general, nab-paclitaxel plus PD-1 inhibitor therapy was relatively well tolerated. Univariate Cox regression analysis showed that patients with angiosarcoma or who experienced three or more AEs had significantly longer PFS.

To the best of our knowledge, this study is the first to report the effectiveness of nab-paclitaxel plus PD-1 inhibitors for the treatment of advanced STS. Since the efficacy of PD-1 inhibitor monotherapy in STSs is extremely low, the use of various methods to reprogram the tumor microenvironment from immune-"cold" to immune-"hot" to increase the sensitivity of PD-1 inhibitors in STS is a promising approach $[18,20]$. Potential mechanisms of the combination therapy of PD-1 inhibitors with cytotoxic chemotherapy agents include immunogenic tumor cell death, anti-angiogenesis, selective depletion of myeloid immunosuppressive cells, reduction of tumor-induced immune suppression, and the sensitization of tumor cells to the immune response [20,29].

\footnotetext{
(See figure on next page.)

Fig. 1 Target lesion changes in patients with soft tissue sarcoma treated with nanoparticle albumin-bound paclitaxel plus a programmed cell death protein 1 inhibitor. A Waterfall plot shows the maximum reduction of target lesion size from baseline evaluated according to the Response Evaluation Criteria for Solid Tumors (RECIST, version 1.1). The horizontal axis represents different patients, and the vertical axis represents the percentage of change in the target lesions. One patient with angiosarcoma had a complete response (100\% decrease in target lesion size), six patients had a partial response (30\% and more decrease in target lesion size), seven patients had stable disease (<20\% increase and $<30 \%$ decrease in target lesion size), and 14 patients had progressive disease (20\% and more increase in target lesion size). B Line plot shows the duration of response of the target lesions from baseline evaluated according to RECIST (version 1.1). Each line represents the change in the size of a patient's target lesion over the time of treatment. Patients with a complete or partial response are indicated in green, those with progressive disease in red, and those with stable disease in yellow
} 

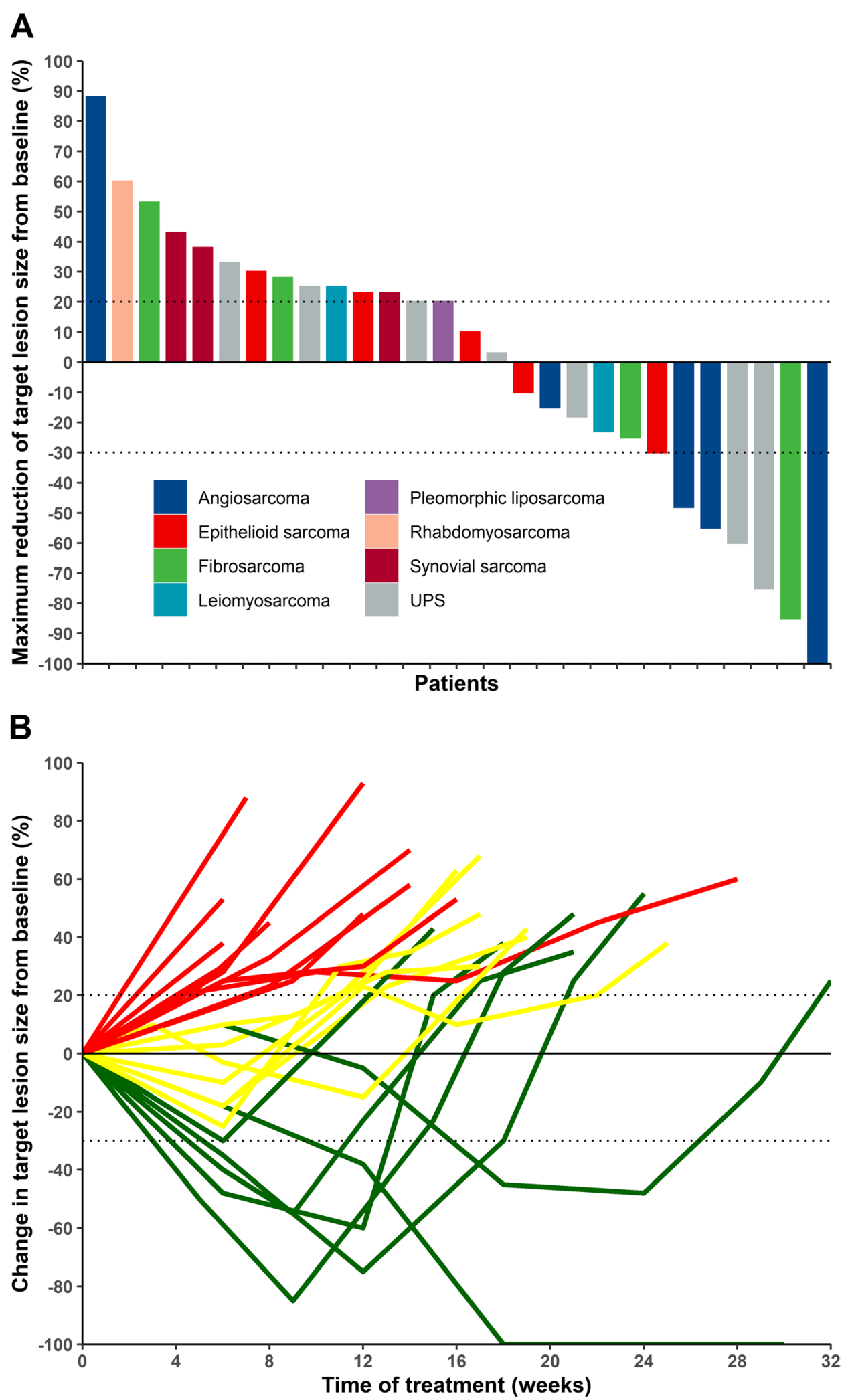

Fig. 1 (See legend on previous page.) 
Table 3 Clinical effectiveness

\begin{tabular}{ll}
\hline Characteristics & Data \\
\hline ORR (\%) & 25.00 (95\%Cl: $10.7-44.9)$ \\
DCR (\%) & 50.00 (95\%Cl: $30.6-69.4)$ \\
M-PFS (months) & $2.25(95 \% \mathrm{Cl}: 1.80-3.00)$ \\
4 months PFS rate (\%) & $17.9(95 \% \mathrm{Cl}: 0.081-0.395)$ \\
6 months PFS rate (\%) & $7.1(95 \% \mathrm{Cl}: 0.019-0.272)$
\end{tabular}

Data are presented as percentages or means. Tumor responses were evaluated according to the Response Evaluation Criteria in Solid Tumors (version 1.1), and were categorized as $C R$ Complete response, $P R$ Partial response, SD Stable disease, or progressive disease. The ORR Objective response rate was defined as the sum of $C R$ and $P R$ rates. $D C R$ Disease control rate was defined as the sum of the ORR and SD. PFS Progression-free survival was calculated from the date of the first nab-paclitaxel plus PD-1 inhibitor treatment until the date of documented progression

Table 4 Adverse events

\begin{tabular}{lll}
\hline Adverse events & Grade 1-2 & Grade 3-4 \\
\hline Alopecia & $89.3 \%(25 / 28)$ & \\
Leucopenia & $25.0 \%(7 / 28)$ & $10.7 \%(3 / 28)$ \\
Fatigue & $21.4 \%(6 / 28)$ & $3.6 \%(1 / 28)$ \\
Anemia & $21.4 \%(6 / 28)$ & \\
Nausea & $21.4 \%(6 / 28)$ & $3.6 \%(1 / 28)$ \\
Peripheral neuropathy & $17.9 \%(5 / 28)$ & $10.7 \%(3 / 28)$ \\
Transaminase increase & $17.9 \%(5 / 28)$ & $7.1 \%(2 / 28)$ \\
Anorexia & $14.3 \%(4 / 28)$ & $3.6 \%(1 / 28)$ \\
Diarrhea & $14.3 \%(4 / 28)$ & $3.6 \%(1 / 28)$ \\
Thrombocytopenia & $14.3 \%(4 / 28)$ & $3.6 \%(1 / 28)$ \\
Hypothyroidism & $14.3 \%(4 / 28)$ & $3.6 \%(1 / 28)$ \\
Pneumonitis & $10.7 \%(3 / 28)$ & \\
Fever & $10.7 \%(3 / 28)$ & \\
Abdominal pain & $7.1 \%(2 / 28)$ & \\
Rash & $3.6 \%(1 / 28)$ & \\
\hline
\end{tabular}

Data are presented as percentages (number events/total). Adverse events were assessed using the National Cancer Institute Common Terminology Criteria for Adverse Events (version 4.0)

Chemotherapy combined with a PD-1 inhibitor has been shown to have a beneficial effect against various other malignancies [20, 25, 29]. Recent clinical trials have demonstrated the efficacy and safety of the combination of the PD-1 inhibitor, pembrolizumab, and the chemotherapy drug, doxorubicin, for treating patients with advanced STS [22, 30]. These results suggest that it is feasible to improve the sensitivity of PD-1 inhibitors by combining them with chemotherapeutic agents. Nab-paclitaxel is a well-known inducer of immunogenic cell death and has been shown to improve the efficacy of PD-1 inhibitors via the regulation of various immune functions [25, 31]. The synergistic effect of nab-paclitaxel combined with a PD-1 inhibitor has been demonstrated [23-25, 32]. Therefore, the aforementioned combination regimen was selected for the treatment of our patients.

The results of this retrospective study showed that the combination regimen was significantly more effective against advanced STS than PD-1 inhibitor monotherapy [19]. Furthermore, our approach was as effective as the use of paclitaxel plus gemcitabine for STS treatment [26, 33 ], indicating that the combination of nab-paclitaxel and a PD-1 inhibitor improves the sensitivity of both the PD-1 inhibitor and nab-paclitaxel toward STS and provides a reference for the further study of this combination regimen. Although the combination regimen in this study was as effective as the administration of paclitaxel plus gemcitabine in STS treatment, the use of nab-paclitaxel plus PD-1 inhibitor has its unique benefits. For instance, the infusion conditions required by nab-paclitaxel or PD-1 inhibitors are simple and convenient, which are important considerations for patient satisfaction. Another important finding was that the combination therapy appeared to have greater efficacy against certain subtypes of sarcomas, particularly angiosarcoma. Therefore, nab-paclitaxel plus PD-1 inhibitor is a strong complement to existing therapies for STSs. However, it should be noted that the median PFS was relatively short for the patients in this study. This may be attributed to the small sample size or a potential problem with the treatment regimen.

In terms of safety, the incidence of AEs was low among patients in this study; grade 3-4 AEs were rare. This suggests that the nab-paclitaxel plus PD-1 inhibitor combination has a favorable safety profile, which is in accordance with the findings of previous studies [24, $32]$; the safety profile of this combination regimen is significantly better than that of paclitaxel plus gemcitabine for STS therapy [26, 33]. This can greatly improve the satisfaction and quality of life of patients undergoing treatment. In addition, univariate analysis showed that patients who experienced a higher number of AEs had longer PFS. This is similar to the results of another study on patients with refractory melanoma, in which significantly longer median PFS $(P<0.05)$ was reported for patients who experienced $\geq 3$ AEs or immune-related AEs during combination therapy with nab-paclitaxel and anti-PD-1 inhibitor [25]. In other words, patients who experienced fewer AEs had poorer outcomes. Therefore, it may be considered to increase the dose of the drug in patients with a low incidence of AEs, thus improving the therapeutic effect.

Our study had some limitations. This includes but is not limited to the relatively low number of patients and short follow-up time, as well as the lack of monitoring patients' immune status during the treatment period. 


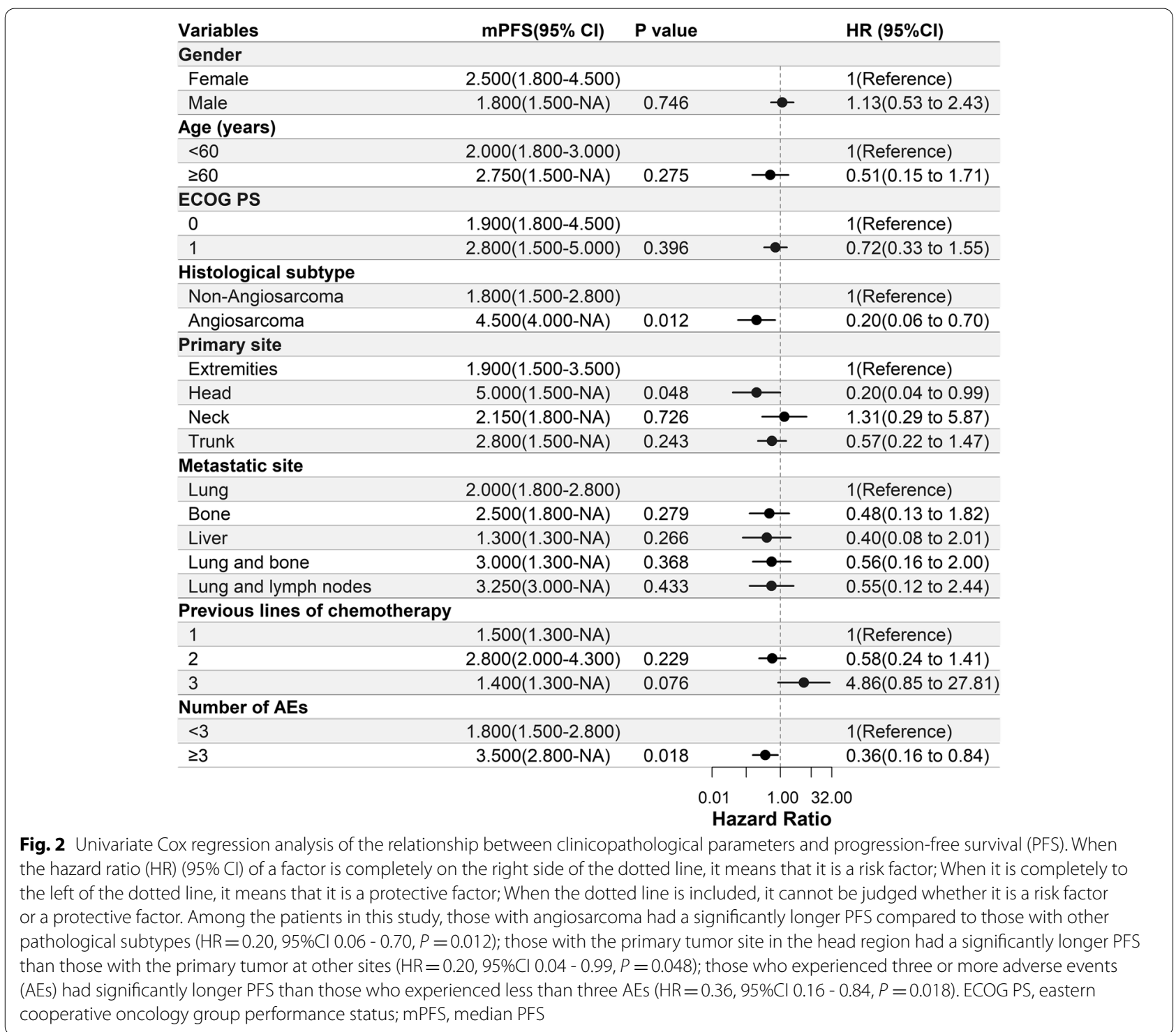

Furthermore, this study also identified some problems that require investigation. First, it is still unknown which drug plays a major role in this combination. Moreover, the potential synergistic mechanisms between these two drugs should be elucidated. The optimal dosage regimen for nab-paclitaxel is also not yet clear. Finally, given that the effect of this combination therapy varied among subtypes of STSs, further clinical studies with larger sample sizes should be conducted to determine which patients would benefit most from this treatment protocol.

\section{Conclusions}

The results of this study demonstrated that a combination of nab-paclitaxel plus PD-1 inhibitor is a promising treatment regimen for advanced STS, and it is worth conducting randomized controlled clinical trials to further demonstrate its efficacy and determine its optimal application scenario.

\section{Abbreviations \\ AE: Adverse events; CR: Complete response; DCR: Disease control rate; nab- paclitaxel: Nanoparticle albumin-bound paclitaxel; ORR: Objective response rate; PD: Progressive disease; PD-1: Programmed cell death protein 1; PFS: Progression-free survival; PR: Partial response; RECIST: Response evaluation criteria in solid tumors; SD: Stable disease; STS: Soft tissue sarcoma.}

\section{Acknowledgments}

The authors are grateful to all the Chinese patients and their family members for their cooperation in the study.

\section{Authors' contributions}

Conception, design and drafting of the study: ZT and WY. Patient recruitment and clinical investigation: ZT, SD, SG, PZ, and XW. Analysis and interpretation of 
data: ZT, Yang Yang, Yonghao Yang and JY. All authors have read and approved the manuscript.

\section{Funding}

Not applicable.

\section{Availability of data and materials}

The datasets used and/or analyzed in the current study are available from the corresponding author on reasonable request.

\section{Declarations}

\section{Ethics approval and consent to participate}

The study was performed in accordance with the principles and guidelines of the Declaration of Helsinki and approved by the Ethics Committee of the Affiliated Cancer Hospital of Zhengzhou University. All patients provided written informed consent.

\section{Consent for publication}

Not applicable.

\section{Competing interests}

The authors declare they have no competing interests.

\section{Author details}

'Department of Bone and Soft Tissue, The Affiliated Cancer Hospital of Zhengzhou University and Henan Cancer Hospital, Dongming Road, Zhengzhou 450008, Henan Province, China. ${ }^{2}$ Huanghe Science and Technology College, Zhengzhou 450063, Henan Province, China. ${ }^{3}$ Department of Immunotherapy, The Affiliated Cancer Hospital of Zhengzhou University and Henan Cancer Hospital, Zhengzhou 450008, Henan Province, China. ${ }^{4}$ Department of Medical Oncology, The Affiliated Cancer Hospital of Zhengzhou University and Henan Cancer Hospital, Zhengzhou 450008, Henan Province, China.

Received: 21 September 2021 Accepted: 5 January 2022

Published online: 12 January 2022

\section{References}

1. Ruggiero A. Bone and soft tissue sarcoma. Cancers (Basel). 2020;12(9). https://doi.org/10.3390/cancers12092609.

2. von Mehren M, Kane JM, Bui MM, Choy E, Connelly M, Dry S, et al. NCCN guidelines insights: soft tissue sarcoma, version 1.2021. J Natl Compr Cancer Netw. 2020;18(12):1604-12. https://doi.org/10.6004/jnccn.2020. 0058.

3. Meyer M, Seetharam M. First-line therapy for metastatic soft tissue sarcoma. Curr Treat Options in Oncol. 2019;20(1):6. https://doi.org/10.1007/ s11864-019-0606-9.

4. Yang Z, Zheng R, Zhang S, Zeng H, Li H, Chen W. Incidence, distribution of histological subtypes and primary sites of soft tissue sarcoma in China. Cancer Biol Med. 2019;16(3):565-74. https://doi.org/10.20892/j.issn.20953941.2019 .0041

5. George S. Developments in systemic therapy for soft tissue and bone sarcomas. J Natl Compr Canc Netw. 2019;17(5.5):625-8. https://doi.org/ 10.6004/jnccn.2019.5020.

6. Wilding CP, Elms ML, Judson I, Tan AC, Jones RL, Huang PH. The landscape of tyrosine kinase inhibitors in sarcomas: looking beyond pazopanib. Expert Rev Anticancer Ther. 2019;19(11):971-91. https://doi.org/10.1080/ 14737140.2019.1686979.

7. Bui NQ, Wang DS, Hiniker SM. Contemporary management of metastatic soft tissue sarcoma. Curr Probl Cancer. 2019;43(4):289-99. https://doi.org/ 10.1016/j.currproblcancer.2019.06.005.

8. Kudlowitz D, Muggia F. Nanoparticle albumin-bound paclitaxel (nab-paclitaxel): extending its indications. Expert Opin Drug Saf. 2014;13(6):681-5. https://doi.org/10.1517/14740338.2014.910193.

9. Cecco S, Aliberti M, Baldo P, Giacomin E, Leone R. Safety and efficacy evaluation of albumin-bound paclitaxel. Expert Opin Drug Saf. 2014;13(4):511-20. https://doi.org/10.1517/14740338.2014.893293.
10. Blair HA, Deeks ED. Albumin-bound paclitaxel: a review in non-small cell lung cancer. Drugs. 2015;75(17):2017-24. https://doi.org/10.1007/ s40265-015-0484-9.

11. Zhang W, Li Y, Xue L, Qu D, Jiang Z, Wang Z, et al. Encouraging pathological complete response rate from neoadjuvant chemotherapy with albumin-bound paclitaxel plus cisplatin and capecitabine for locally advanced esophageal squamous carcinoma: preliminary outcome of a retrospective study. Cancer Manag Res. 2021;13:2163-70. https://doi.org/ 10.2147/CMAR.S298360.

12. Yoneshima Y, Morita S, Ando M, Nakamura A, Iwasawa S, Yoshioka H, et al. Phase 3 trial comparing nanoparticle albumin-bound paclitaxel with docetaxel for previously treated advanced NSCLC. J Thorac Oncol. 2021;16(9):1523-32. https://doi.org/10.1016/j.jtho.2021.03.027.

13. Kim JS, Suh KJ, Lee DW, Woo GU, Kim M, Kim SH, et al. A real-world efficacy of nab-paclitaxel monotherapy in metastatic breast cancer. Cancer Res Treat. 2021. https://doi.org/10.4143/crt.2021.394.

14. Amoroso L, Castel V, Bisogno G, Casanova M, Marquez-Vega C, Chisholm $\mathrm{JC}$, et al. Phase II results from a phase I/II study to assess the safety and efficacy of weekly nab-paclitaxel in paediatric patients with recurrent or refractory solid tumours: a collaboration with the European Innovative Therapies for Children with Cancer Network. Eur J Cancer. 2020;135:8997. https://doi.org/10.1016/j.ejca.2020.04.031.

15. Oesterheld JE, Reed DR, Setty BA, Isakoff MS, Thompson P, Yin H, et al. Phase II trial of gemcitabine and nab-paclitaxel in patients with recurrent Ewing sarcoma: a report from the National Pediatric Cancer Foundation. Pediatr Blood Cancer. 2020;67(7):e28370. https://doi.org/10.1002/pbc. 28370.

16. Metts JL, Alazraki AL, Clark D, Amankwah EK, Wasilewski-Masker KJ, George BA, et al. Gemcitabine/nab-paclitaxel for pediatric relapsed/ refractory sarcomas. Pediatr Blood Cancer. 2018;65(9):e27246. https://doi. org/10.1002/pbc.27246.

17. Saerens M, Brusselaers N, Rottey S, Decruyenaere A, Creytens D, Lapeire L. Immune checkpoint inhibitors in treatment of soft-tissue sarcoma: a systematic review and meta-analysis. Eur J Cancer. 2021;152:165-82. https:// doi.org/10.1016/.ejca.2021.04.034.

18. Rytlewski J, Milhem MM, Monga V. Turning 'cold'tumors 'hot': immunotherapies in sarcoma. Ann Transl Med. 2021;9(12):1039. https://doi.org/10. 21037/atm-20-6041.

19. Tawbi HA, Burgess M, Bolejack V, Tine BAV, Schuetze SM. Pembrolizumab in advanced soft-tissue sarcoma and bone sarcoma (SARC028): a multicentre, two-cohort, single-arm, open-label, phase 2 trial. Lancet Oncol. 2017;18(11):1493-501. https://doi.org/10.1016/S1470-2045(17)30624-1.

20. Salas-Benito D, Perez-Gracia JL, Ponz-Sarvise M, Rodriguez-Ruiz ME, Martinez-Forero I, Castanon E, et al. Paradigms on immunotherapy combinations with chemotherapy. Cancer Discov. 2021;11(6):1353-67. https://doi.org/10.1158/2159-8290.CD-20-1312.

21. Clemente O, Ottaiano A, Di Lorenzo G, Bracigliano A, Lamia S, Cannella $\mathrm{L}$, et al. Is immunotherapy in the future of therapeutic management of sarcomas? J Transl Med. 2021;19(1):173. https://doi.org/10.1186/ s12967-021-02829-y.

22. Livingston MB, Jagosky MH, Robinson MM, Ahrens WA, Benbow JH, Farhangfar CJ, et al. Phase II study of pembrolizumab in combination with doxorubicin in metastatic and unresectable soft tissue sarcoma. Clin Cancer Res. 2021. https://doi.org/10.1158/1078-0432.CCR-21-2001.

23. Shen D, Wang J, Wu J, Chen S, Li J, Liu J, et al. Neoadjuvant pembrolizumab with chemotherapy for the treatment of stage IIIB-IIIB resectable lung squamous cell carcinoma. J Thorac Dis. 2021;13(3):1760-8. https:// doi.org/10.21037/jtd-21-103.

24. Patel SA, Gerber DE, Deal A, Douglas K, Pecot CV, Lee C, et al. Consolidation with pembrolizumab and nab-paclitaxel after induction platinumbased chemotherapy for advanced non-small cell lung cancer. Front Oncol. 2021;11:666691. https://doi.org/10.3389/fonc.2021.666691.

25. Li JJ, Wang JH, Dingv Y, Li DD, Wen XZ, Zhao JJ, et al. Efficacy and safety of anti-PD-1 inhibitor combined with nab-paclitaxel in Chinese patients with refractory melanoma. J Cancer Res Clin Oncol. 2021. https://doi.org/ 10.1007/s00432-021-03700-9.

26. Tian Z, Zhang F, Li P, Wang J, Yang J, Zhang P, et al. Albumin-bound paclitaxel and gemcitabine combination therapy in soft tissue sarcoma. BMC Cancer. 2020;20(1):698. https://doi.org/10.1186/s12885-020-07199-0.

27. Tian Z, Wang J, Yang J, Zhang $P$, Wang $X$, Zhang F, et al. Apatinib with doxorubicin and ifosfamide as neoadjuvant therapy for high-risk soft 
tissue sarcomas: a retrospective cohort study. Investig New Drugs. 2021. https://doi.org/10.1007/s10637-021-01139-w.

28. Eisenhauer EA, Therasse P, Bogaerts J, Schwartz LH, Sargent D, Ford R, et al. New response evaluation criteria in solid tumours: revised RECIST guideline (version 1.1). Eur J Cancer. 2009;45(2):228-47. https://doi.org/ 10.1016/j.ejca.2008.10.026.

29. He M, Yang T, Wang Y, Wang M, Chen $X$, Ding $D$, et al. Immune checkpoint inhibitor-based strategies for synergistic cancer therapy. Adv Healthc Mater. 2021;10(9):e2002104. https://doi.org/10.1002/adhm.202002104.

30. Pollack SM, Redman MW, Baker KK, Wagner MJ, Schroeder BA, Loggers $E T$, et al. Assessment of doxorubicin and pembrolizumab in patients with advanced anthracycline-naive sarcoma: a phase 1/2 nonrandomized clinical trial. JAMA Oncol. 2020;6(11):1778-82. https://doi.org/10.1001/ jamaoncol.2020.3689.

31. Chen Y, Liu R, Li C, Song Y, Liu G, Huang Q, et al. Nab-paclitaxel promotes the cancer-immunity cycle as a potential immunomodulator. Am J Cancer Res. 2021;11(7):3445-60.

32. Zhang F, Huang D, Zhao L, Li T, Zhang S, Zhang G, et al. Efficacy and safety of PD-1/PD-L1 inhibitors plus nab-paclitaxel for patients with non-small cell lung cancer who have progressed after platinum-based chemotherapy. Ther Adv Med Oncol. 2020;12:1758835920936882. https://doi.org/10. $1177 / 1758835920936882$.

33. Seddon B, Strauss SJ, Whelan J, Leahy M, Woll PJ, Cowie F, et al. Gemcitabine and docetaxel versus doxorubicin as first-line treatment in previously untreated advanced unresectable or metastatic soft-tissue sarcomas (GeDDiS): a randomised controlled phase 3 trial. Lancet Oncol. 2017:18(20):1397-410. https://doi.org/10.1016/S1470-2045(17)30622-8.

\section{Publisher's Note}

Springer Nature remains neutral with regard to jurisdictional claims in published maps and institutional affiliations.

- fast, convenient online submission

- thorough peer review by experienced researchers in your field

- rapid publication on acceptance

- support for research data, including large and complex data types

- gold Open Access which fosters wider collaboration and increased citations

- maximum visibility for your research: over $100 \mathrm{M}$ website views per year

At BMC, research is always in progress.

Learn more biomedcentral.com/submissions 